\title{
Epidemiology and Changes in Patient-Related Factors from 1997 to 2009 in Clinical Yeast Isolates Related to Dermatology, Gynaecology, and Paediatrics
}

\author{
Viktor Czaika, ${ }^{1}$ Pietro Nenoff, ${ }^{2}$ Andreas Glöckner, ${ }^{3}$ Wolfgang Fegeler, \\ Karsten Becker, ${ }^{4}$ and Arno F. Schmalreck ${ }^{5}$ \\ ${ }^{1}$ Klinik für Dermatologie, Venerologie und Allergologie, Campus Benjamin Franklin, Charité-Universitätsmedizin Berlin, \\ Hindenburgdamm 30, 12203 Berlin, Germany \\ ${ }^{2}$ Laboratorium für medizinische Mikrobiologie, Straße des Friedens 8, 04579 Mölbis, Germany \\ ${ }^{3}$ BDH-Klinik Greifswald GmbH, Karl-Liebknecht-Ring 26a, 17491 Greifswald, Germany \\ ${ }^{4}$ Institute of Medical Microbiology, Domagkstraße 10, 48149 Münster, Germany \\ ${ }^{5}$ MBS-Microbiology, P.O. Box 101247, 80086 Munich, Germany
}

Correspondence should be addressed to Arno F. Schmalreck; muenchen-mbs@t-online.de

Received 27 April 2013; Revised 30 June 2013; Accepted 1 July 2013

Academic Editor: Isabel Sá-Correia

Copyright (C) 2013 Viktor Czaika et al. This is an open access article distributed under the Creative Commons Attribution License, which permits unrestricted use, distribution, and reproduction in any medium, provided the original work is properly cited.

From 1997 to 2009, 1,862 dermatology, gynaecology, and paediatrics (DGP) associated clinical yeast isolates were analysed for species occurrence, specimen origin and type, (multi-) resistance pattern, and testing period. The top seven of the isolated DGPassociated species remained the same as compared to total medical wards, with Candida albicans (45\%) as most frequent pathogen. However, the DGP wards and DGP ICUs showed species-specific profiles; that is, the species distribution is clinic-specific similar and however differs in their percentage from ward to ward. By applying the "one fungus one name" principle, respectively, the appropriate current taxonomic species denominations, it has been shown that no trend to emerging species from 1998 to 2008 could be detected. In particular the frequently isolated non-Candida albicans species isolated in the DGP departments have already been detected in or before 1997. As yeasts are part of the cutaneous microbiota and play an important role as opportunistic pathogens for superficial infections, proper identification of the isolates according to the new nomenclature deems to be essential for specific and calculated antifungal therapy for yeast-like DGP-related infectious agents.

\section{Introduction}

Superficial fungal infections are often chronic and recurring. It has been estimated that approximately $15 \%$ of the population has fungal infections of the skin (tinea pedis or athlete's foot) or nails (onychomycosis) or of the feet. These infections are common in older children and adults [1]. Distal subungual, proximal, subungual, and white superficial onychomycoses are usually caused by dermatophytes, but Candida spp. may be present in all types in less than $1 \%$ of these cases [2]. In the past, yeasts are thought to be simply skin contaminants [3]; however, yeasts and nondermatophyte moulds may also cause toenail onychomycosis [4-8]. A higher proportion of yeasts is generally found in onychomycosis, where dermatophytes (68\%), yeasts (29\%), and moulds (3\%) are the most causative fungal pathogens [9]. Some Candida spp. causing onychomycosis were reported to be partly resistant to oral antifungal agents (AFAs). In patients with chronic mucocutaneous infections, the main yeast pathogen is Candida (C.) albicans, but $C$. tropicalis, $C$ parapsilosis, Issatchenkia (I.) orientalis, and Meyerozyma (M.) guilliermondii may also contribute to these infections [10].

It has been suggested by Clayton and Noble [11] that the spread of yeasts in the hospital ward occurs in a similar way to the spread of Staphylococcus aureus. In addition, the carriage rates of yeasts on the skin in hospital patients appear to be higher than those in the nonhospital population [11]. As cutaneous sites may act as common sources of infection, 
the ability of patients to disseminate bacteria and yeasts is to a greater extent due to the colonization of the skin, and to the fact that such patients liberate more particles of the skin than persons with a clinically normal skin [12]. As with C. albicans, the non-C. albicans Candida (NCAC) infections within 276 NCAC (14\%) of 1,972 Candida isolates, as reported by Somerville [13], contribute to a significant amount to the hospital acquired infections.

Species distribution within the not-Candida yeasts (NCY), for example, of Trichosporon spp., which are emerging in Asian countries [14], may be strongly influenced by antifungal agent use [15]. Parallel to the increasing rate of dermatological infections by NCAC and NCY species, an increasing number of these usually opportunistic pathogens $[14,16-19]$ are isolated of critically ill patients $[20,21]$, from the oral cavity $[22,23]$, in pulmonary infections [24], from cutaneous (intertriginous, paronychianous) and mucocutaneous (vulvovaginal, balanitinous) infections [25-27], genitourinary tract infections $[28,29]$, and in the intensive care unit [30]. The most common fungal infections in infants and children are mucocutaneous candidiasis, pityriasis versicolor, tinea corporis, tinea pedis, and tinea capitis [27]. Candida colonization has a considerable prevalence among paediatric and neonatal patients [31-35]. Preterm newborns in the paediatric ICU where besides vaginal delivery, low birth weight, and low gestational, age can be considered as risk factor for colonization [36]. Oropharyngeal candidiasis (thrush) may start as early as seven days after birth, with an incidence in infants of $5 \%$ to $10 \%$ depending on the population studied $[31,37,38]$.

Aside of the changing epidemiology of classical and emerging human fungal infections [39], the incidence of atopic dermatitis (AD), a multifactorial disease in which both hereditary and environmental factors play a role, has been increasing. The worldwide prevalence of $\mathrm{AD}$ is about $10 \%-20 \%$ in children and $1 \%-3 \%$ in adults [40-42]. In a total of 241 samples in a Lithuania clinic of patients with clinical diagnosis of $\mathrm{AD}$ exacerbation, most isolated genera were $27.4 \%$ Candida, 6.6\% Malassezia, and 2.9\% Rhodotorula mucilaginosa. The species most frequently isolated in child and adult groups were Debaromyces hansenii, C. pelliculosa, C. parapsilosis, and Malassezia furfur [42-44].

Therefore, precise strain identification and knowledge of the epidemiology of Candida and NAC species are essential and are of great advantage in making and optimizing treatment decisions, especially when the phylogenetic relationship of the expected isolates [45] is additionally considered.

The aim of this reevaluation, after renaming the isolates according to their currently valid taxonomic denomination, was to evaluate the distribution and occurrence rate of the relevant yeast species, isolated from dermatology, gynaecology, and paediatric (DGP) patients. By using the "new nomenclature" this study should build a valid basis for the comparison of recent and future fungal epidemiological surveys. The actual susceptibility profile and its possible changes during the isolation period (1998-2008) of the 1,862 clinical DGPyeast isolates, tested against frequently used azole antifungal agents in this area, are given in a corresponding paper [46].

\section{Material and Methods}

The 1,862 clinical yeast isolates (Table 1) were derived from dermatology, gynaecology, and paediatric wards from German University hospitals in Berlin (Charité), Dresden, Leipzig, Münster, and Munich (Ludwig-MaximiliansUniversität München, and Technische Universität München) starting at the end of 1997 until February 2009, in the framework of 4 multicenter studies (MCS) [49-51]. The few numbers of strains $(n<40)$ of the years 1997 and 2009 were added to those isolates of 1998 and 2008, respectively. Therefore, the time period throughout this paper is referenced as 1998 to 2008. In addition, as no MCS were performed from 2005 to 2007, respectively, no DGP clinics participated; therefore isolates from this time period are missing. For comparison and possible trend recognition additionally, and with respect to the number of isolates, two similar test periods (19982001 and 2002-2008) have been set up out of the total studyperiod.

Identification and differentiation of the isolates were performed using methods routinely employed at the microbiology/mycology laboratories of the participating test centres. Confirmatory identification was made for unusual or notidentified species by FTIR and/or PCR at the appropriate reference laboratory of the individual multicenter study. As the "one fungus one name" principle is effective since 2013 [52, 53], the current valid names for the appropriate species were applied throughout this paper as published in SpeciesFungorum [47], respectively, in MycoBank [48].

Susceptibility testing of these isolates was performed by microdilution against relevant azole antifungal agents, as described in the corresponding paper [46].

To ease the evaluation and setting of tables the patientrelated factors such as clinical specialities (different wards), origin and type of specimen were merged and subsumed in large groups, for example, aspirates (transtracheal, limbic, materials from punctures, e.g., abscess, bursa, pericardial, pleura, rectum, and pus); catheters (indwelling, vascular, venereal, ports, and anaesthetic tube); sterile fluids (sterile body fluids, liquor, dialysates, BAL, tracheal secrets, pleura, lachrymal, synovial, and serum, except blood and urine); solid (sterile) materials (tissue/lung tissue, bone-marrow, throat discharge/sputum, abscess, spleen, bone, liver, stomach, and ear); devices (contact lenses, artificial joints, dialysis access, haemodialysis grafts, cardiac devices such as heart valves, pacemakers, ICDs, VADs, central nervous system devices, penile implants, vaginal sponges, diaphragms, and intrauterine devices); dermatological materials (skin scrapings, nails/nail scrapings, plucked hair, dandruff, and scales); gynaecological materials (scrapings, genital-, prostate secrets, ejaculate), urine (mid-stream, punctuate, and catheter); external (external clinics, doctors office, and external laboratory); general medicine (allergology, angiology, bronchoscopy, dialysis, endocrinology, gastroenterology, geriatrics, internal medicine, emergency room, endocrinology, nephrology, pneumology, policlinics, psychiatry, rheumatology, rehabilitation centre, standard care, HIV centre, and tropical medicine); swabs (surfaces, all body parts, wounds, skin, 


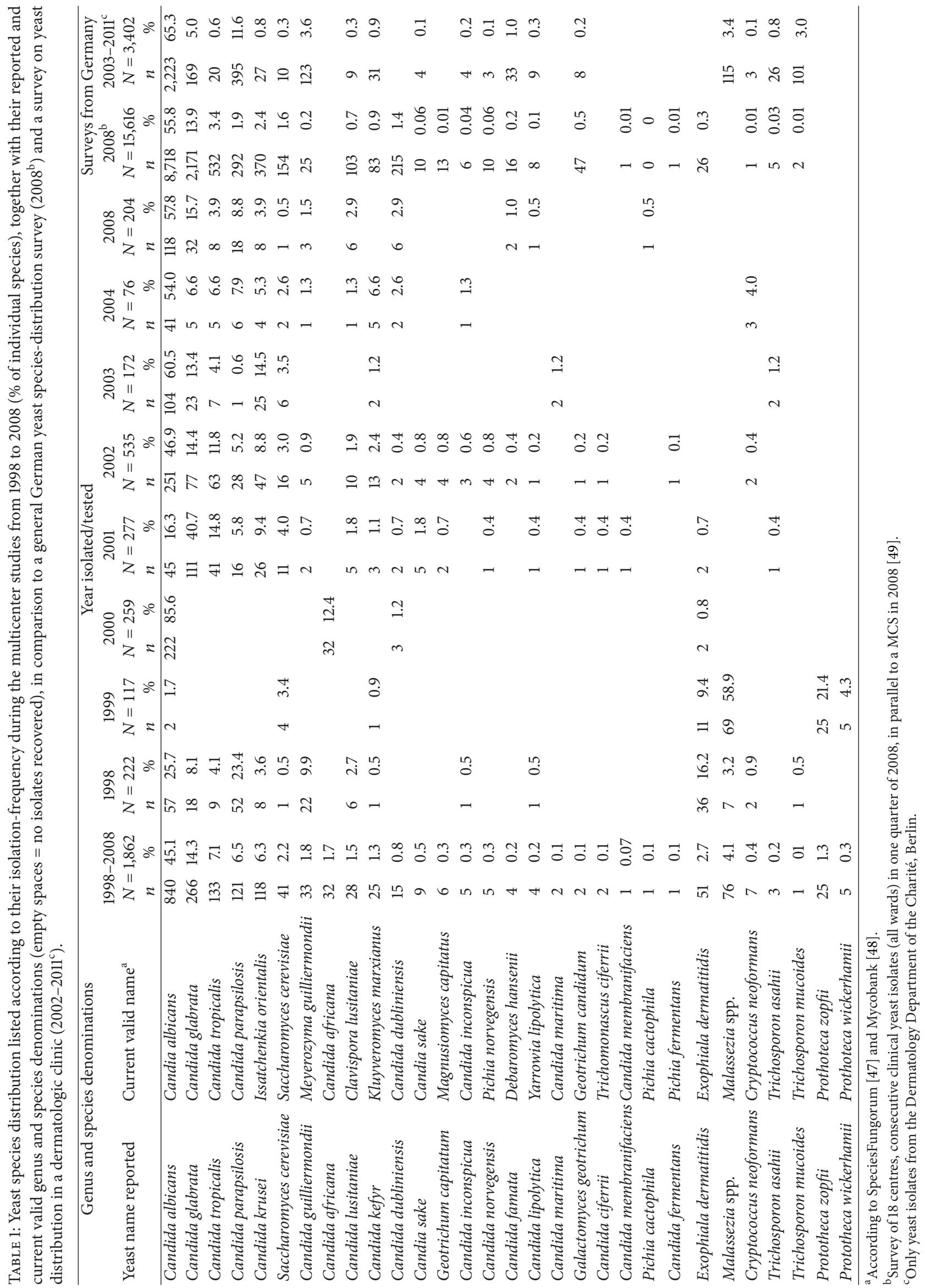




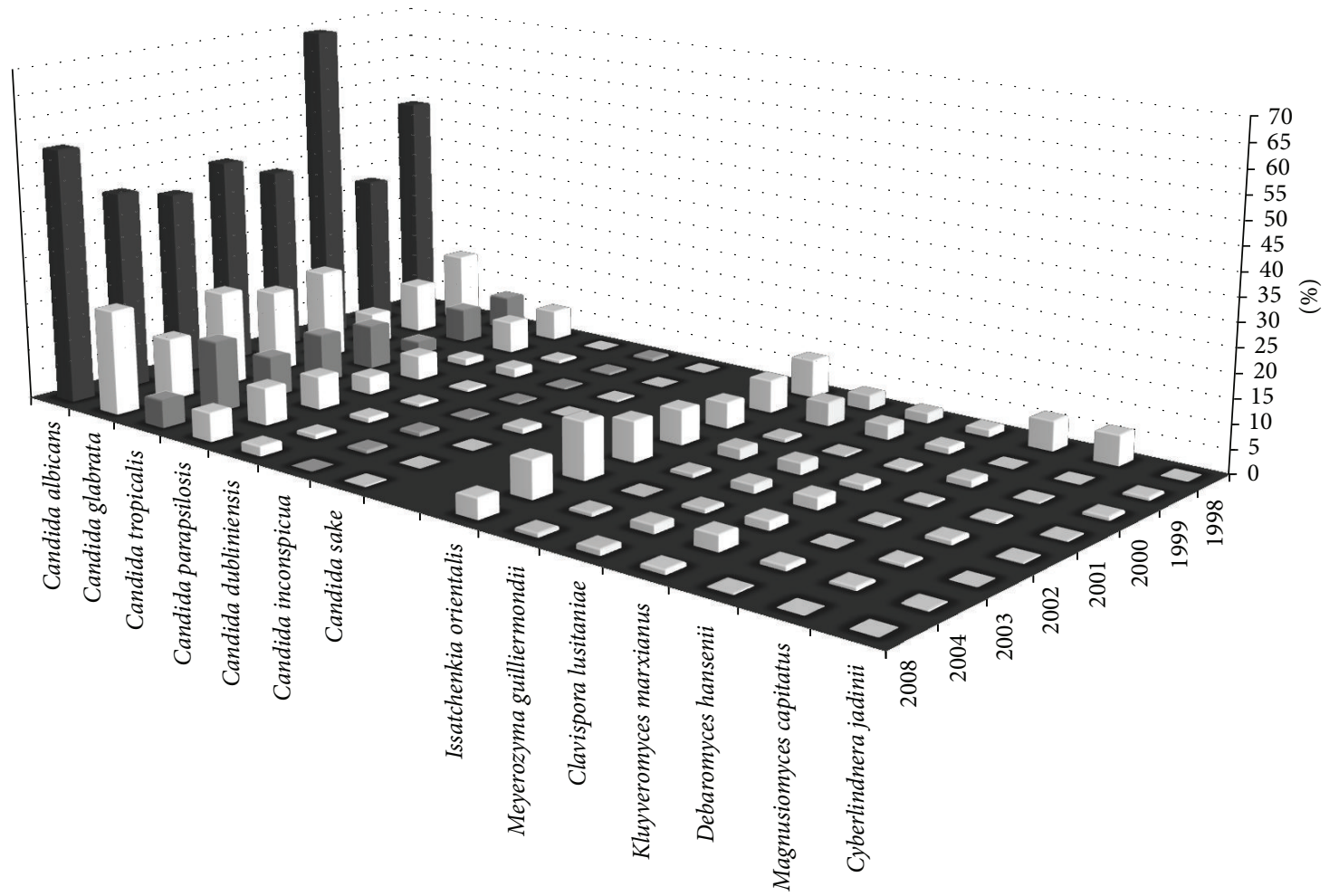

FIGURE 1: Distribution of the most frequently isolated DGP-related Candida and non-Candida species from 1998 to 2008.

stoma, ear, and bone), surgery (abdominal, aesthetic, general, heart, plastic, vascular, and neurosurgery).

\section{Results and Discussion}

3.1. Species Distribution. The distribution according to their isolation frequency of clinical Candida and NCY species isolated during the MCS from 1998 to 2008 of DGP patients is shown in Table 1. Candida and NCY species most frequently recovered are displayed in Figure 1 by their distribution of the year of isolation. As the "one fungus one name" principle is effective from the beginning of 2013 [51], the current valid taxonomic denominations for genera and species $[47,53]$ were listed in parallel to the reported species names by the test centres (Table 1). The "new" genus/species names were used throughout this paper. As consequence of the speciesrenaming, a substantial reduction in species assigned to the genus "Candida" and a raise of "new" species occurred. Thus, of the Candida clade [37] of 19 Candida species reported, nine $(47 \%)$ had to be renamed, and the namechanges were not only restricted to the Candida species. The "new" ("emerging") taxons, partly called before "notCandida albicans Candida," "not-Candida yeasts," or "cryptic" pathogens [16-18, 34, 54-58], were already widely present at the beginning of and found throughout the German multicenter studies [49-51].

Despite the "new" taxonomy, Candida species remain to be the most frequent pathogens with C. glabrata, $C$. parapsilosis, C. tropicalis, C. inconspicua, and on top $C$. albicans, causing the majority of fungal infections in the DGP area $[25,35]$. Although the most prevailing species in all three wards (DGP) is C. albicans, its percentage of occurrence differs significantly (Table 2). Candia krusei and C. guilliermondii, which also belong to the class of the 8 most frequent agents to cause fungal infections, are now to be found under the taxonomic designations Issatchenkia orientalis and Meyerozyma guilliermondii. When compared to the isolation rates of clinical yeast isolates from total medical wards (Table 1; survey 2008), the ranking of isolated DGP-related species differs somewhat; however, the top seven of the isolated species remained the same, as also shown by the corresponding data from a recent dermatology ward survey (Table 1). Interestingly, the species distribution of the 10 years study is similar to the survey conducted in 2008 for the general yeast distribution in Germany (Table 1), whereas the distribution of the dermatophytes from 1998 to 2008 (Table 2) is similar to the survey from 2003 to 2011 within a dermatology unit (Table 1). The predominance of yeasts in both surveys and the study agrees with other studies performed elsewhere $[10,59]$, with $C$. parapsilosis as the second frequent dermatology associated pathogen. As nationally/internationally reported for invasive fungal diseases (IFD) and Candida blood stream infections [54, 55, 58-64], the isolation frequency of the major pathogens from the DGP wards (Tables 1 and 2) followed the change of IFD in Europe [65] and mirrors the changing occurrences of Candida and NCY strains. Thus the "valid" Candida species were most prevalent among the DGP strains with $76.5 \%$ of the total isolates (Tables 1 and 2), including Candida 


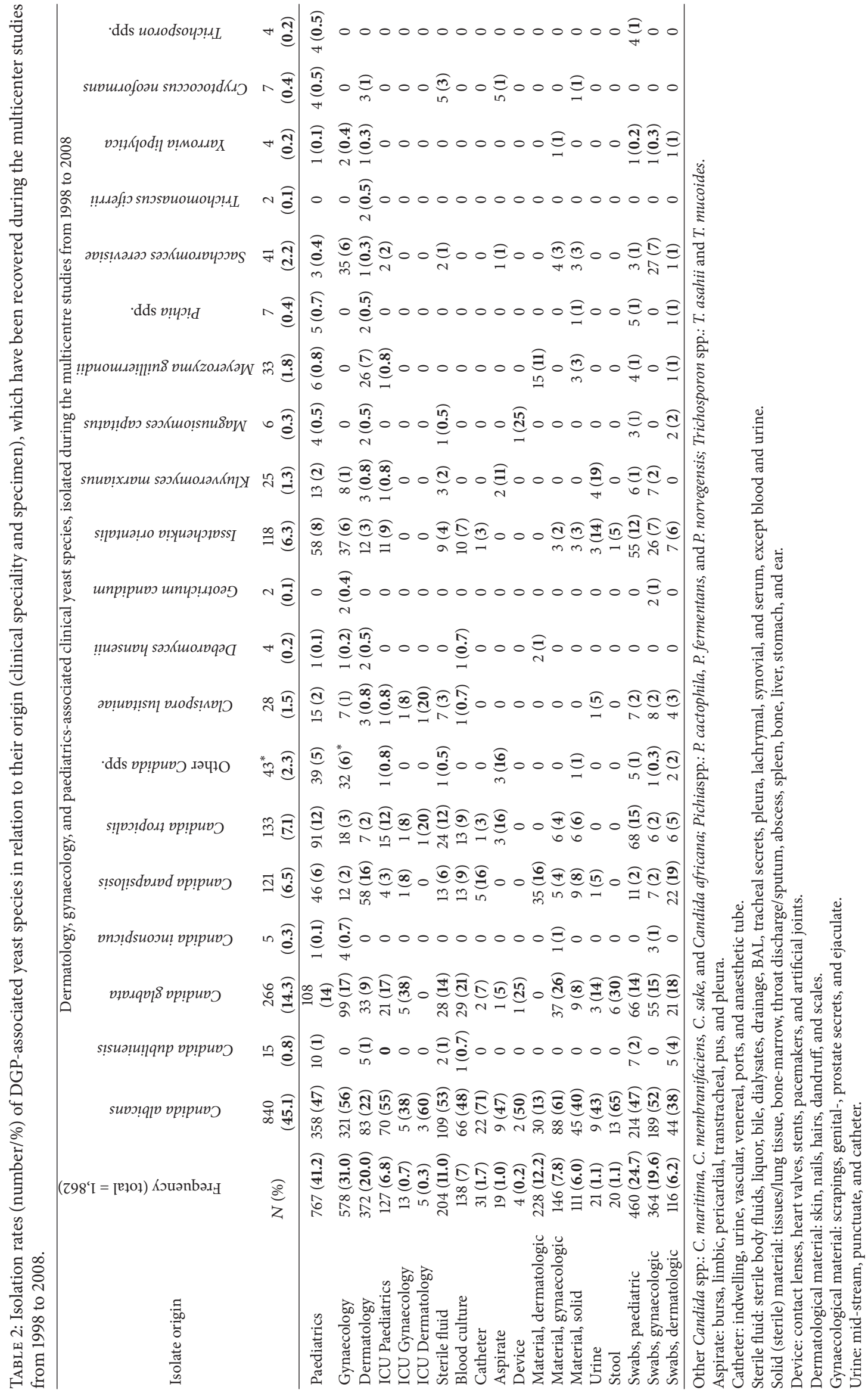


TABLE 3: Occurrence differences, respectively, of profiles of the most frequent isolated yeast species (number/percentage (\% of species)) in the DGP wards and DGP ICUs.

\begin{tabular}{lcccccc}
\hline Ward/ICU & $N$ (total) & C. albicans $(\mathbf{8 4 0})$ & C. glabrata(266) & C. parapsilosis(121) & C. tropicalis (133) & M. guilliermondii(33) \\
\hline Dermatology & 372 & $83 / 22.3(\mathbf{9 . 9})$ & $33 / 8.9(\mathbf{1 2 . 4})$ & $58 / 15.6(\mathbf{4 7 . 9})$ & $7 / 1.9(\mathbf{5 . 3})$ & $26 / 7.0(\mathbf{7 8 . 8})$ \\
Gynaecology & 578 & $321 / 55.5(\mathbf{3 8 . 2})$ & $99 / 17.1(\mathbf{3 7 . 2})$ & $12 / 2.1(\mathbf{9 . 9})$ & $18 / 3.1(\mathbf{1 3 . 5})$ & $\mathbf{0}$ \\
Paediatrics & 767 & $358 / 46.7(\mathbf{4 2 . 6})$ & $108 / 14.1(\mathbf{4 0 . 6})$ & $46 / 6.0(\mathbf{3 8 . 0})$ & $91 / 11.9(\mathbf{6 8 . 4})$ & $\mathbf{6} / 0.8(\mathbf{1 8 . 2})$ \\
D-ICU & 5 & $3 / 60.0(\mathbf{0 . 4})$ & $\mathbf{0}$ & $\mathbf{0}$ & $1 / 20.0(\mathbf{0 . 8})$ & $\mathbf{0}$ \\
G-ICU & 13 & $5 / 38.5(\mathbf{0 . 6})$ & $5 / 38.5(\mathbf{1 . 9})$ & $1 / 7.7(\mathbf{0 . 8})$ & $1 / 7.7(\mathbf{0 . 8})$ & $\mathbf{0}$ \\
P-ICU & 127 & $70 / 55.1(\mathbf{8 . 3})$ & $21 / 16.5(\mathbf{7 . 9})$ & $4 / 3.2(\mathbf{3 . 3})$ & $15 / 11.8(\mathbf{1 1 . 3})$ & $1 / 0.8(\mathbf{3 . 0})$ \\
\hline
\end{tabular}

albicans (59\% thereof; $45 \%$ of total isolates), followed by the ascomycetous NCY species (17\%), and the basidiomycetous yeasts with 3\%. Besides C. albicans (D: 22\%, G: 56\%, P: $47 \%)$, the only species isolated from all DGP wards and its ICUs were C. tropicalis $(2 \%, 3 \%, 12 \%)$ and Clavispora $(\mathrm{Cl}$. lusitaniae (1\%, 1\%, 2\%).

Despite the uneven distribution and low testing rates of some clinical isolates throughout the study periods, the isolation rate demonstrated a slight, statistically not significant increase of the NCY species (Figure 1). Nevertheless, in the DGP wards, the increase in NCA strains followed those found in the other medical specialities $[15,16,20,21,26,29,34,54$, $55,61,64,66]$. A summary of the distribution of Candida species in epidemiological surveys of the last decades was given in [66-68]. The most frequent isolates from all the DGP ICUs $(N=145)$ were C. albicans (54\%), C. glabrata (18\%), C. tropicalis (12\%), I. orientalis (8\%), C. parapsilosis (3\%), Cl. lusitaniae (3\%), Saccharomyces (S.) cerevisiae (1\%), C. sake, Kluyveromyces (K.) marxianus, and M. guilliermondii $(0.7 \%$ each). Somewhat different isolation rates were reported for ICUs strains in France [68] and Turkey [69], where ICU isolates (France/Turkey) accounted for 57\%/14\% C. albicans, $17 \% / 4 \%$ C. glabrata, $8 \% / 28 \%$ C. parapsilosis, 5\%/4\% I. orientalis, and $5 \% / 14 \%$ C. tropicalis and in Turkey only 3\% K. marxianus, 2\% Wickerhamomyces anomalus, $1 \% M$. guilliermondii, 1\% C. dubliniensis, 0.6\% Debaromyces (D.) hansenii, and $0.3 \%$ Clavispora lusitaniae.

It has been reported that C. parapsilosis was most frequently recovered from younger patients, decreasing with age, while C. glabrata occurrence increased with age [70]. Whereas the frequency of C. parapsilosis in the DGP wards and DGP ICUs (except dermatology ICUs) were found at $16 \%$ (D), 6\% (P), 2\% (G), 8\% G-ICU, and 3\% P-ICU, C. tropicalis was found at $12 \%(\mathrm{P}), 3 \%(\mathrm{G}), 2 \%(\mathrm{D}), 20 \%$ (D-ICU), $12 \% \mathrm{P}-$ ICU, and at $8 \%$ in the G-ICU (Table 2).

Aside from C. albicans, the highest prevalence was found for C. glabrata with $17 \%(\mathrm{G}), 14 \%$ (D), 9\% (P), 38\% (GICU), and $17 \%$ (P-ICU). In a Hospital-Infection-SurveillanceStudy in Germany [71] evaluating nosocomial infections in the ICU, C. albicans was found to be the most frequently pathogen causing vascular catheter associated sepsis $(5.6 \%$ in all ICUs, $2.8 \%$ in paediatric ICUs), and the fourth most agent of urinary catheter associated UTI infections (8.7\%). The distribution of the yeast species in the Turkish paediatric ICU was $2 \% / 4 \% / 1 \%$ for C. albicans, C. parapsilosis, and D. hansenii. No other species from this ICU had been reported. Although the incidence of candidemia was stable over a ten-year period (0.5 episodes/10.000 patient days per year), it was five times higher in ICUs than in other surgical wards in Switzerland [72]. However, during the recent decades a progressive shift from a predominance of $C$. albicans towards NCAC/NCY species (including C. glabrata and I. orientalis) has been reported [73], with C. glabrata accounting for $15 \%-20 \%$ of infections in most countries [74-76]. These differences in the occurrences of the most important and regularly isolated yeast species in the DGP wards and ICUs of the study are demonstrated in Table 3. C. parapsilosis and M. guilliermondii are most prominent only in the dermatology wards $(48 \% / 79 \%)$ and found to a significant lesser extent in the paediatrics units $(28 \% / 18 \%)$ but not at all in the gynaecology wards. Compared to the dermatology units the levels of C. albicans and C. glabrata are about $30 \%$ higher in gynaecology and paediatrics, whereas $C$. parapsilosis occurrence is about $30 \%$ higher in dermatology and paediatrics than in gynaecology wards. The occurrence of C. tropicalis (Table 3) is highest in paediatric wards (68\%) and significantly lower in gynaecology (14\%) and dermatology (5\%).

Romeo and Criseo [77] found that 8 out of their $11 \mathrm{C}$. dubliniensis isolates were derived from oral specimens, and only 2 were found in vaginal and one in gastric fluid. Of the 15 C. dubliniensis strains in this study, one was isolated from blood, 2 from sterile body fluids, 5 from dermatological, and 7 from paediatric swabs. No C. dubliniensis, C. inconspicua, and D. hansenii isolates were derived from DGP ICUs (Table 2) and none of these strains were found in DGP-specimens, except DGP swabs (Table 2). Gumral et al. [78] reported the lack of $C$. dubliniensis and C. africana strains in Turkey with vaginal C. albicans isolates, whilst Nnadi et al. [79] found in Nigeria no C. dubliniensis in vulvovaginal samples. As three C. africana isolates appeared in Berlin and two in Munich they were tested during a MCS in 2000, together with the strains from Angola and Madagascar. Although so far considered only as a new subspecies of C. albicans, C. africana should be reconsidered as separate species according to the original proposal of Tietz et al. [80]. This is supported by the results of Forche et al. [81] that rDNS sequences of C. dubliniensis differ significantly from those of $C$. albicans and that $C$. africana isolates are phylogenetically different. Moreover, $C$. africana could clearly be separated by FT-IR [82], probably nowadays by Matrix Assisted Laser-Desorption/Ionisation Time-Of-Flight Mass Spectroscopy (MALDITOF MS) as for C. dubliniensis [83], by pyrosequencing [84], or as described with a specific molecular method [85]. All these methods 
demonstrated that they are able to discriminate distinctly between the very closely related species $C$. albicans, $C$. africana, and C. dubliniensis. Apart from the reported isolates in the study and those from vaginal specimens from Africa $[80,81]$, none appeared in further German/Austrian MCS, and only a few strains were isolated later in Italy [77, 85], Spain [86], Nigeria [79], and Great Britain [84].

Protothecosis is a sporotrichosis-like infection in humans, in both immunocompromised and immunocompetent patients, and in animals. It is caused by achlorophyllic algae of the genus Prototheca, which belongs to the family Chloracellae and is rarely involved in human infections [87, 88]. The genus Prototheca (P.) consists currently of 6 species: P. wickerhamii, P. zopfii, P. stagnora, P. ulmea, P. blaschkeae, and P. cutis. P. zopfii contains currently two genotypes [89]. Species of the genus Prototheca exist in the environment as ubiquitous detritus inhabitants and contaminants of various substrates. General protothecosis is caused in humans mainly by $P$. wickerhamii and in domestic animals by $P$. zopfii. General symptoms are dermatitis or bovine mastitis, whereas mortal cases are extremely rare. $P$. wickerhamii and $P$. zopfii were isolated in 1998 in an outbreak in a children's unit during one of the MCS, where these organisms were transmitted from pet animals to the patients [82].

Of the twelve different species of Malassezia (M.) yeast described [90-92], M. furfur (14/0.2\%), M. globosa (2/0.02\%), M. obtusa (1/0.01\%), M. pachydermatis (1/0.01\%), M. sloofiae (1/0.01\%), and M. sympodialis (55/3\% of total, $72.3 \%$ of $M$. spp.) have been isolated during the investigations in 1998 and 1999. This parallels the report of Petry et al. [91], where $M$. sympodialis (72\%) was the most frequently isolated Malassezia species. In addition, Petry et al. [91] reported that the back and the chest of the patients are the most common sites of the lesions, and no statistically significant difference was found between species as a function of gender, age, or the duration of the lesions [92]. Malassezia is strongly associated with dandruff, a common scalp disorder, although not all individuals with Malassezia on their skin develop dandruff. Besides Malassezia spp., which contribute by $5 \%$ to the population from dandruff-afflicted scalps, Filobasidium filoforme was reported to be the most isolated basidiomycete, whereas in healthy scalps Cryptococcus spp. (90\%), together with Rhodotorula mucilaginosa, are detectable [92]. Whilst during the MCS of 1998 to 2008 Cryptococcus neoformans had been isolated 7 times ( $0.4 \%$ of total isolates), no Rhodotorula spp. infections were observed during the MCS. In addition, due to the limited time frame of the MCS within a study year, none of the Exophiala, Malassezia, and Prototheca species have been isolated anymore during the German/Austrian MCS up to 2009, with the exception of E. dermatitidis of which two strains each have been isolated in the MCS of 1999 and 2000 and of the two separate outbreaks of Malassezia and Prototheca spp. in 1998/99 (Table 1).

The opportunistic yeast pathogen Trichosporon (T.) asahii, which is part of the cutaneous fungal microbiota in humans, was isolated occasionally from 1998 to 2008 (0.2\% of total isolates). T. asahii may be one of the routes through which deep-seated trichosporonosis is acquired, whereas environmental T. asahii is not associated with this infection [93].

The DGP-species distribution of urine samples was somewhat different to those isolated in a survey from 2003 to 2004 from urine specimens of 100 hospitalized patients in a Turkish hospital who had nosocomial candiduria [94].

With $80 \%$ to $95 \%, C$. albicans is the predominant vaginal colonizing species in premenopausal and pregnant asymptotic and healthy women with acute Candida vaginitis and chronically recurrent vulvovaginal candidosis. NCACspecies, especially C. glabrata, are more frequent in postmenopausal, in diabetic and immunosuppressed women, paralleled by regional differences in the distribution of Candida species [95]. The results of this study illustrate that the yeast spectrum in gynaecological wards and its ICUs did not change significantly. This is in accordance with the findings by Mendling and Brasch [95], who reported at least for Germany no evidence of an increase of NCAC/NCY species in either acute or recurrent vaginal candidosis.

3.2. Specimen Distribution. The distribution of specimens according to its origin is given in Table 2. According to the different clinic specialities, the specimen types and their amount differed from those of their corresponding ICUs (Table 2). However, the ranking and type of the isolated pathogenic yeast species resembled the first five yeast pathogens from invasive fungal infections. Only C. albicans was found in all specimen types listed (Table 2), and $C$. glabrata, C. parapsilosis, and Issatchenkia orientalis have been isolated from most of the types of specimens at various percentages (C. albicans: 13\%-71\%; C. glabrata: 5\%-38\%; C. parapsilosis: $2 \%-19 \%$; C. tropicalis: $2 \%-20 \%$; I. orientalis: $2 \%-7 \%)$. All other species were differently attributed to the various specimens. The most frequent isolates from blood cultures (Table 2) were C. albicans (48\%), C. glabrata $(21 \%)$ C. parapsilosis and C. tropicalis (9\%, each), I. orientalis (7\%), and $C$. dubliniensis (1\%), with the percentages related to the total of each individual isolate of $8 \%, 11 \%, 11 \%, 10 \%, 9 \%, 12 \%$, and $7 \%$, respectively.

As shown in Table 2, only 4 devices (0.2\%) have been sent for determination of associated fungi. Three devices were derived from the dermatology and one device from the paediatric ward. From the isolated species thereof $(C$. albicans, C. glabrata, and Magnusiomyces capitatus), at least two of them belong to the numerous Candida species (e.g., C. glabrata, C. parapsilosis, C. tropicalis, C. dubliniensis, and I. orientalis), which are reported to form biofilms, catheterrelated blood-stream, and device-related infections [96-98]. As it was not mandatory for the in vitro multicenter studies to report detailed epidemiological data, the voluntarily gathered data were insufficient to evaluate more patient-related factors.

\section{Conclusions}

About $20-25 \%$ of the world's population is affected by skin mycoses, thus being one of the most frequent forms of infection [99]. The epidemiological trend in skin mycoses 
worldwide is paralleled to changes of nosocomial and invasive fungal infections. Although a significant shift in the distribution of the infection causing agents is reported for dermatology, gynaecology, and paediatric wards, apart from some local breakouts with Malassezia, Prototheca, and Exophiala species, all the infection-causing agents have been present before and throughout the 10-year study period. Aside from significant differences in the species profiles of the DGP wards, a trend in the distribution of the DGPspecies could not be detected and the overall aetiology has not changed during the time period of the multicenter studies from 1997 to 2009. But, besides the typical skin pathogens like C. albicans, C. glabrata, C. parapsilosis, C. tropicalis, C. dubliniensis, and C. inconspicua, infections with atypical, rare, or "cryptic" yeast isolates, which all have been existent, such as Issatchenkia orientalis, Saccharomyces cerevisiae, Meyerozyma guilliermondii, Kluyveromyces marxianus, Clavispora lusitaniae, Debaromyces hansenii, and Yarrowia lipolytica, tend also to emerge in the DGP wards and DGP ICUs, respectively, as reported for the other wards. This may be markedly amplified by the taxonomic changes which are to be implemented since the beginning of 2013 comprising taxonomic reclassifications and concomitant (partially) renaming of various species according to the "one fungus one name" principle. However, this novel practice based on the phylogenetic mapping of the species may allow in future a better association of different or similar pathogens to clinical entities and characteristics. This may also lead to a better and reliable assessment of in vitro susceptibility data (given in a corresponding paper [46]), which represent the basis not only for specific antifungal therapy, but in particular also for calculated ("empiric") antifungal therapy.

\section{Conflict of Interests}

The authors declare that they have no conflict of interests.

\section{Acknowledgment}

To perform and report this study no financial support from pharmaceutical or other companies or from a national or international funding source was received.

\section{References}

[1] J. C. Gentles and E. G. V. Evans, "Foot infections in swimming baths," British Medical Journal, vol. 3, no. 5874, pp. 260-262, 1973.

[2] T. J. Zuber and K. Baddam, "Superficial fungal infection of the skin: where and how it appears help determine therapy," Postgraduate Medicine, vol. 109, no. 1, pp. 117-132, 2001.

[3] M. A. Ghannoum, R. A. Hajjeh, R. Scher et al., "A large-scale North American study of fungal isolates from nails: the frequency of onychomycosis, fungal distribution, and antifungal susceptibility patterns," Journal of the American Academy of Dermatology, vol. 43, no. 4, pp. 641-648, 2000.

[4] M. M. Walshe and M. P. English, "Fungi in nails," British Journal of Dermatology, vol. 78, no. 4, pp. 198-207, 1966.
[5] S. L. Noble, R. C. Forbes, and P. L. Stamm, "Diagnosis and management of common tinea infections," American Family Physician, vol. 58, no. 1, pp. 163-174, 1998.

[6] A. K. Gupta and M.-J. Ricci, "Diagnosing onychomycosis," Dermatologic Clinics, vol. 24, no. 3, pp. 365-369, 2006.

[7] M. R. Vander Straten, M. A. Hossain, and M. A. Ghannoum, "Cutaneous infections dermatophytosis, onychomycosis, and tinea versicolor," Infectious Disease Clinics of North America, vol. 17, no. 1, pp. 87-112, 2003.

[8] E. G. V. Evans, "Resistance of Candida species to antifungal agents used in the treatment of onychomycosis: a review of current problems," British Journal of Dermatology, Supplement, vol. 141, no. 56, pp. 33-35, 1999.

[9] C. Mügge, U.-F. Haustein, and P. Nenoff, "Causative agents of onychomycosis-a retrospective study," Journal der Deutschen Dermatologischen Gesellschaft, vol. 4, no. 3, pp. 218-228, 2006 (German).

[10] M. A. Hossain and M. A. Ghannoum, "New developments in chemotherapy for non-invasive fungal infections," Expert Opinion on Investigational Drugs, vol. 10, no. 8, pp. 1501-1511, 2001.

[11] Y. M. Clayton and W. C. Noble, "Observations on the epidemiology of Candida albicans," Journal of Clinical Pathology, vol. 19, no. 1, pp. 76-78, 1966.

[12] W. C. Noble, "The contribution of individual patients to the spread of infection," British Journal of Dermatology, vol. 85, no. 1, pp. 24-29, 1971.

[13] D. A. Somerville, "Yeasts in a hospital for patients with skin diseases," Journal of Hygiene, vol. 70, no. 4, pp. 667-675, 1972.

[14] M. A. Slavin and A. Chakrabarti, "Opportunistic fungal infections in the Asia-Pacific region," Medical Mycology, Early Online, pp. 1-8, 2011.

[15] S. N. Leaw, H. C. Chang, R. Barton, J.-P. Bouchara, and T. C. Chang, "Identification of medically important Candida and non-Candida yeast species by an oligonucleotide array," Journal of Clinical Microbiology, vol. 45, no. 7, pp. 2220-2229, 2007.

[16] E. M. Johnson, "Rare and emerging Candida species," Current Fungal Infection Reports, vol. 3, no. 3, pp. 152-159, 2009.

[17] M. H. Miceli, J. A. Díaz, and S. A. Lee, "Emerging opportunistic yeast infections," The Lancet Infectious Diseases, vol. 11, no. 2, pp. 142-151, 2011.

[18] P. Vandeputte, S. Ferrari, and A. T. Coste, "Antifungal resistance and new strategies to control fungal infections," International Journal of Microbiology, vol. 2012, Article ID 713687, 26 pages, 2012.

[19] M. Ruhnke, "Epidemiology of Candida albicans infections and role of non-Candida albicans yeasts," Current Drug Targets, vol. 7, no. 4, pp. 495-504, 2006.

[20] S. K. Fridkin, "The changing face of fungal infections in health care settings," Clinical Infectious Diseases, vol. 41, no. 10, pp. 1455-1460, 2005.

[21] A. K. Paswan, D. C. Raju, D. K. Singh, S. Khuba, and R. K. Dubey, "Isolation and distribution of Candida species among different clinical situations in critically ill patients: prospective study," International Journal of Biomedical Research, vol. 3, pp. 120-126, 2012.

[22] J. H. Meurman, E. Siikala, M. Richardson, and R. Rautema, "Non-Candida albicansCandida yeast of the oral cavity," Communicating Current Research and Educational Topics and Trends in Applied Microbiology, 2007, http://www.formatex. org/microbio/pdf/pages719-731.pdf. 
[23] F. Gallè, M. Sanguinetti, G. Colella et al., "Oral candidosis: characterization of a sample of recurrent infections and study of resistance determinants," New Microbiologica, vol. 34, no. 4, pp. 379-389, 2011.

[24] J. B. Varkey and J. R. Perfect, "Rare and emerging fungal pulmonary infections," Seminars in Respiratory and Critical Care Medicine, vol. 29, no. 2, pp. 121-131, 2008.

[25] C. Seebacher, C. D. Abeck, J. Brasch et al., "Candidiasis of the skin," Journal der Deutschen Dermatologischen Gesellschaft, vol. 4, pp. 591-596, 2006 (German).

[26] N. S. Ryder, S. Wagner, and I. Leitner, "In vitro activities of terbinafine against cutaneous isolates of Candida albicans and other pathogenic yeasts," Antimicrobial Agents and Chemotherapy, vol. 42, no. 5, pp. 1057-1061, 1998.

[27] A. K. Gupta, E. A. Cooper, J. E. Ryder, K. A. Nicol, M. Chow, and M. M. Chaudhry, "Optimal management of fungal infections of the skin, hair, and nails," American Journal of Clinical Dermatology, vol. 5, no. 4, pp. 225-237, 2004.

[28] J. M. Achkar and B. C. Fries, "Candida infections of the genitourinary tract," Clinical Microbiology Reviews, vol. 23, no. 2, pp. 253-273, 2010

[29] J. F. Fisher, "Candida urinary tract infections-epidemiology, pathogenesis, diagnosis, and treatment: executive summary," Clinical Infectious Diseases, vol. 52, no. 6, pp. S429-S432, 2011.

[30] P. Fournier, C. Schwebel, D. Maubon et al., "Antifungal use influences Candida species distribution and susceptibility in the intensive care unit," Journal of Antimicrobial Chemotherapy, vol. 66, no. 12, pp. 2880-2886, 2011.

[31] K. M. Butler and C. J. Baker, "Candida: an increasingly important pathogen in the nursery," Pediatric Clinics of North America, vol. 35, no. 3, pp. 543-563, 1988.

[32] D. A. Kaufman, "Challenging issues in neonatal candidiasis," Current medical research and opinion, vol. 26, no. 7, pp. 1769$1778,2010$.

[33] A. Diana, M. Epiney, M. Ecoffey, and R. E. Pfister, "White dots on the placenta and red dots on the baby": congential cutaneous candidiasis - a rare disease of the neonate," Acta Paediatrica, International Journal of Paediatrics, vol. 93, no. 7, pp. 996-999, 2004.

[34] D. K. Benjamin Jr., B. J. Stoll, M. G. Gantz et al., "Neonatal candidiasis: epidemiology, risk factors, and clinical judgment," Pediatrics, vol. 126, no. 4, pp. e865-e873, 2010.

[35] J. Robinson, "Fungal skin infections in children," Nursing Standard, vol. 27, pp. 52-54, 2012.

[36] G. Yousef Ali, E. Hussein, S. S. Algohary, K. Ahmed Rashed, M. Almoghanum, and A. AbdelRahman Khalifa, "Prevalence of Candida colonization in preterm newborns and VLBW in neonatal intensive care unit: role of maternal colonization as a risk factor in transmission of disease," Journal of Maternal-Fetal and Neonatal Medicine, vol. 25, pp. 789-795, 2012.

[37] J. E. Baley, R. M. Kliegman, B. Boxerbaum, and A. A. Fanaroff, "Fungal colonization in the very low birth weight infant," Pediatrics, vol. 78, no. 2, pp. 225-232, 1986.

[38] K. N. Smolinski, S. S. Shah, P. J. Honig, and A. C. Yan, "Neonatal cutaneous fungal infections," Current Opinion in Pediatrics, vol. 17, no. 4, pp. 486-493, 2005.

[39] K. H. Abu-Elteen and M. A. Hamad, "Changing epidemiology of classical and emerging fungal infections: a review," Jordan Journal of Biological Sciences, vol. 5, pp. 215-230, 2012.

[40] S. P. DaVeiga, "Epidemiology of atopic dermatitidis: a review," Allergy and Asthma Proceedings, vol. 33, pp. 227-234, 2012.
[41] H. C. Williams, "Epidemiology of human atopic dermatitisseven areas of notable progress and seven areas of notable ignorance," Veterinary Dermatology, vol. 24, pp. 3-9.e1-3-9.e2, 2013.

[42] A. Zinkeviciene, N. Vaiciulioniene, I. Baranauskiene, V. Kvedariene, R. Emuzyte, and D. Citavicius, "Cutaneous yeast microflora in patients with atopic dermatitis," Central European Journal of Medicine, vol. 6, no. 6, pp. 713-719, 2011.

[43] H. R. Ashbee and E. G. V. Evans, "Immunology of diseases associated with Malassezia species," Clinical Microbiology Reviews, vol. 15, no. 1, pp. 21-57, 2002.

[44] S. M. Yim, J. Y. Kim, J. H. Ko, Y. W. Lee, Y. B. Choe, and K. J. Ahn, "Molecular analysis of malassezia microflora on the skin of the patients with atopic dermatitis," Annals of Dermatology, vol. 22, no. 1, pp. 41-47, 2010.

[45] A. F. Schmalreck, M. Lackner, K. Becker, W. Fegeler, V. Czaika, and C. L. Florl, "Phylogenetic relationship mattersantifungal susceptibility among clinically relevant yeast-like fungi," accepted by AAC for publication.

[46] V. Czaika, P. Nenoff, A. Glöckner, K. Becker, W. Fegeler, and A. F. Schmalreck, "Epidemiology and changes in patient-related factors from 1997 until 2009 in clinical yeast isolates related to dermatology, gynaecology, and paediatrics," International Journal of Microbiology, vol. 2013, Article ID 703905, 2013.

[47] IndexFungorum, 2013, http://www.indexfungorum.org.

[48] MycoBank, 2013, http://www.mycobank.org/.

[49] A. F. Schmalreck, B. Willinger, G. Haase et al., "Species and susceptibility distribution of 1062 clinical yeast isolates to azoles, echinocandins, flucytosine and amphotericin B from a multicentre study," Mycoses, vol. 55, no. 3, pp. e124-e137, 2012.

[50] A. F. Schmalreck, "Empfindlichkeitsprüfung von Fluconazol: Auswertung einer Multizenter-Studie der Arbeitsgemeinschaft "Klinische Mykologie" der Deutschsprachigen Mykologischen Gesellschaft," Mycoses, vol. 39, supplement 2, pp. 1-11, 1998 (German).

[51] Rationale für Bewertungskriterien für minimale Hemmkonzentrationen (MHK) und Hemmzonendurchmesser (HZD) von Fluconazol entsprechend DIN 58940 bei klinisch relevanten Sprosspilzen, sowie Festlegung von Fluconazol-(Grenz)Kontrollwerten für Kontrollstämme, vol. 157 of DIN-Fachbericht, DIN-Fachbericht, Beuth, Berlin, Germany, 2007, (German).

[52] J. M. McNeill, F. R. Barrie, W. R. Buck et al., Eds., International Code of Nomenclature for Algae, Fungi, and Plants (Melbourne Code) Adopted by the Eighteens International Botanical Congress Melbourne, Australia, A.R.G. Ganter, Ruggell, 2012, http://www.imafungus.org/Issue/31/22.pdf.

[53] L. L. Norvell, "Melbourne approves a new code," Mycotaxon, vol. 116, pp. 481-490, 2011.

[54] M. D. Richardson, "Changing patterns and trends in systemic fungal infections," Journal of Antimicrobial Chemotherapy, vol. 56, no. 1, pp. i5-ill, 2005.

[55] S. Giri and A. J. Kindo, "A review of Candida species causing blood stream infection," Indian Journal of Medical Microbiology, vol. 30, pp. 270-278, 2012.

[56] M. A. Pfaller, L. N. Woosley, S. A. Messer, R. N. Jones, and M. Castanheira, "Significance of molecular identification and antifungal susceptibility of clinically significant yeasts and moulds in a global antifungal surveillance program," Mycopathologia, vol. 174, pp. 259-271, 2012.

[57] I. Miranda-Zapico, E. Eraso, J. L. Hernández-Almaraz et al., "Prevalence and antifungal susceptibility patterns of new cryptic species inside the species complexes Candida parapsilosis 
and Candida glabrata among blood isolates from a Spanish tertiary hospital," Journal of Antimicrobial Chemotherapy, vol. 66, no. 10, Article ID dkr298, pp. 2315-2322, 2011.

[58] K. Alby and R. J. Bennett, "Sexual reproduction in the Candida clade: cryptic cycles, diverse mechanisms, and alternative functions," Cellular and Molecular Life Sciences, vol. 67, no. 19, pp. 3275-3285, 2010.

[59] A. Tragiannidis, W. Fegeler, G. Rellensmann et al., "Candidaemia in a European Paediatric University Hospital: a 10-year observational study," Clinical Microbiology and Infection, vol. 18, no. 2, pp. E27-E30, 2012.

[60] K. Paredes, D. A. Sutton, J. Cano et al., "Molecular identification and antifungal susceptibility testing of clinical isolates of the Candida rugosa species complex and proposal of the new species Candida neorugosa," Journal of Clinical Microbiology, vol. 50, pp. 2397-2403, 2012.

[61] G. Morace, E. Borghi, R. Latta et al., "Antifungal susceptibility of invasive yeast isolates in Italy: the GIIA3 study in critically ill patients," BMC Infectious Diseases, vol. 11, p. 130, 2011.

[62] M. A. Pfaller, D. J. Diekema, D. L. Gibbs et al., "Results from the artemis disk global antifungal surveillance study, 1997 to 2007: a 10.5-year analysis of susceptibilities of Candida species to fluconazole and voriconazole as determined by CLSI standardized disk diffusion," Journal of Clinical Microbiology, vol. 48, no. 4, pp. 1366-1377, 2010.

[63] M. B.-V. Zepelin, L. Kunz, R. Rüchel, U. Reichard, M. Weig, and U. Groß, "Epidemiology and antifungal susceptibilities of Candida spp. to six antifungal agents: results from a surveillance study on fungaemia in Germany from July 2004 to August 2005," Journal of Antimicrobial Chemotherapy, vol. 60, no. 2, pp. 424-428, 2007.

[64] R. Fleck, A. Dietz, and H. Hof, "In vitro susceptibility of Candida species to five antifungal agents in a German university hospital assessed by the reference broth microdilution method and Etest," Journal of Antimicrobial Chemotherapy, vol. 59, no. 4, pp. 767-771, 2007.

[65] C. Lass-Flörl, "The changing face of epidemiology of invasive fungal disease in Europe”, Mycoses, vol. 52, no. 3, pp. 197-205, 2009.

[66] A. C. Rodloff, D. Koch, and R. Schaumann, "Epidemiology and antifungal resistance in invasive candidiasis," European Journal of Medical Research, vol. 16, no. 4, pp. 187-195, 2011.

[67] P. Billie and J. Marchetti, "Diagnosis of invasive candidiasis in the ICU," Annals of Intensive Care, vol. 1, p. 37, 2011.

[68] O. Leroy, J.-P. Gangneux, P. Montravers et al., "Epidemiology, management, and risk factors for death of invasive Candida infections in critical care: a multicenter, prospective, observational study in France (2005-2006)," Critical Care Medicine, vol. 37, no. 5, pp. 1612-1618, 2009.

[69] G. Ece, P. Samlioglu, G. Akkoclu, S. Atalay, and S. Kose, “The evaluation of the distribution of yeast like fungi," International Journal of Medical Sciences, vol. 9, pp. 617-620, 2012.

[70] C. Paulo, C. Mourão, P. M. Veiga et al., "Retrospective analysis of clinical yeast isolates in a hospital in the centre of Portugal: spectrum and revision of the identification procedures," Medical Mycology, vol. 47, no. 8, pp. 836-844, 2009.

[71] C. Geffers and P. Gastmeier, "Nosocomial infections and multidrug-resistant organisms in Germany: epidemiological data from KISS (The Hospital Infection Surveillance System)," Ärzteblatt International, vol. 108, no. 6, pp. 87-93, 2011 (German).
[72] O. Marchetti, J. Bille, U. Fluckiger et al., "Epidemiology of candidemia in Swiss tertiary care hospitals: secular trends, 19912000," Clinical Infectious Diseases, vol. 38, no. 3, pp. 311-320, 2004.

[73] M. H. Nguyen, J. E. Peacock Jr., A. J. Morris et al., “The changing face of candidemia: emergence of non-Candida albicans species and antifungal resistance," American Journal of Medicine, vol. 100, no. 6, pp. 617-623, 1996.

[74] R. Latha, R. Sasikala, N. Muruganandam, and R. Venkatesh Babu, "Study on the shifting patterns of non Candida albicans Candida in lower respiratory tract infections and evaluation of the CHROM agar in identification of the Candida species," Journal of Microbiology and Biotechnology Research, vol. 1, pp. 113-119, 2011.

[75] M. Bassetti, E. Righi, A. Costa et al., "Epidemiological trends in nosocomial candidemia in intensive care," BMC Infectious Diseases, vol. 6, 2006.

[76] M. Méan, O. Marchetti, and T. Calandra, "Bench-to-bedside review: Candida infections in the intensive care unit," Critical Care, vol. 12, no. 1, article 204, 2008.

[77] O. Romeo and G. Criseo, "Molecular epidemiology of Candida albicans and its closely related yeasts Candida dubliniensis and Candida africana," Journal of Clinical Microbiology, vol. 47, no. 1, pp. 212-214, 2009.

[78] R. Gumral, B. Sancak, A. B. Guzel, M. A. Saraçli, and M. Ilkit, "Lack of Candida africana and Candida dubliniensis in Vaginal Candida albicans Isolates in Turkey using HWP1 gene polymorphisms," Mycopathologia, vol. 172, no. 1, pp. 73-76, 2011.

[79] N. E. Nnadi, G. M. Ayanbimpe, F. Scordino et al., "Isolation and molecular characterization of Candida africana from Jos, Nigeria," Mycology, vol. 50, pp. 765-757, 2012.

[80] H.-J. Tietz, M. Hopp, A. Schmalreck, W. Sterry, and V. Czaika, "Candida africana sp. nov., a new human pathogen or a variant of Candida albicans?" Mycoses, vol. 44, no. 11-12, pp. 437-445, 2001.

[81] A. Forche, G. Schönian, Y. Gräser, R. Vilgalys, and T. G. Mitchell, "Genetic structure of typical and atypical populations of Candida albicans from Africa," Fungal Genetics and Biology, vol. 28, no. 2, pp. 107-125, 1999.

[82] A. F. Schmalreck, P. Tränkle, E. Vanca, and R. BlaschkeHellmessen, "Differenzierung und Charakterisierung von humanpathogenen Hefen (Candida albicans, Exophiala dermatitidis) und tierpathogenen Algen (Prototheca spp.) mittels Fourier-Transform-Infrarot-Spektroskopie (FT-IR) im Vergleich zu konventionellen Methoden," Mycoses, vol. 41, supplement 1, pp. 71-77, 1998.

[83] H. Hof, U. Eigner, T. Maier, and P. Staib, "Differentiation of Candida dubliniensis from Candida albicans by means of MALDI-TOF mass spectrometry," Clinical Laboratory, vol. 58, pp. 927-931, 2012.

[84] A. M. Borman, A. Szekely, and E. M. Johnson EM, "Epidemiology, antifungal susceptibility and pathogenicity of Candida africana isolates from the United Kingdom," Journal of Clinical Microbiology, vol. 51, Article ID 233035, pp. 967-972, 2013.

[85] O. Romeo and G. Criseo, "First molecular method for discriminating between Candida africana, Candida albicans, and Candida dubliniensis by using hwpl gene," Diagnostic Microbiology and Infectious Disease, vol. 62, no. 2, pp. 230-233, 2008.

[86] R. Alonso-Vargas, L. Elorduy, E. Eraso et al., "Isolation of Candida africana, probable atypical strains of Candida albicans, from a patient with vaginitis," Medical Mycology, vol. 46, no. 2, pp. 167-170, 2008. 
[87] F. Leliaert, D. R. Smith, H. Moreau et al., "Phylogeny and molecular evolution of the green algae," Critical Reviews in Plant Sciences, vol. 31, no. 1, pp. 1-46, 2012.

[88] C. Lass-Flörl and A. Mayr, "Human protothecosis," Clinical Microbiology Reviews, vol. 20, no. 2, pp. 230-242, 2007.

[89] U. Roesler, A. Möller, A. Hensel, D. Baumann, and U. Truyen, "Diversity within the current algal species Prototheca zopfii: a proposal for two Prototheca zopfii genotypes and description of a novel species, Prototheca blaschkeae sp. nov," International Journal of Systematic and Evolutionary Microbiology, vol. 56, no. 6, pp. 1419-1425, 2006.

[90] A. Kalinowska-Pujdak, A. Schmalreck, U.-F. Haustein, and P. Nenoff, "Species differentiation of yeasts of the genus Malassezia with Fourier transform infrared spectroscopy," Hautarzt, vol. 57, no. 2, pp. 127-136, 2006 (German).

[91] V. Petry, F. Tanhausen, L. Weiss, T. Milan, A. Mezzari, and M. B. Weber, "Identification of Malassezia yeast species isolated from patients with pityriasis versicolor," Anais Brasileiros de Dermatologia, vol. 86, no. 4, pp. 803-806, 2011.

[92] H. K. Park, M.-H. Ha, S.-G. Park, M. N. Kim, B. J. Kim, and W. Kim, "Characterization of the fungal microbiota (mycobiome) in healthy and dandruff-afflicted human scalps," PLoS ONE, vol. 7, no. 2, Article ID e32847, 2012.

[93] E. Zhang, T. Sugita, R. Tsuboi, T. Yamazaki, and K. Makimura, "The opportunistic yeast pathogen Trichosporon asahii colonizes the skin of healthy individuals: analysis of 380 healthy individuals by age and gender using a nested polymerase chain reaction assay," Microbiology and Immunology, vol. 55, no. 7, pp. 483-488, 2011.

[94] B. Ozhak-Baysan, D. Ogunc, D. Colak et al., "Distribution and antifungal susceptibility of Candida species causing nosocomial candiduria," Medical Mycology, vol. 50, pp. 529-532, 2012.

[95] W. Mendling and J. Brasch, "Guideline vulvovaginal candidosis (2010) of the german society for gynecology and obstetrics, the working group for infections and infectimmunology in gynecology and obstetrics, the german society of dermatology, the board of german dermatologists and the german speaking mycological society," Mycoses, vol. 55, no. 3, pp. 1-13, 2012.

[96] E. M. Kojic and R. O. Darouiche, "Candida infections of medical devices," Clinical Microbiology Reviews, vol. 17, no. 2, pp. 255267, 2004.

[97] C. Von Eiff, B. Jansen, W. Kohnen, and K. Becker, "Infections associated with medical devices: pathogenesis, management and prophylaxis," Drugs, vol. 65, no. 2, pp. 179-214, 2005.

[98] G. Ramage, R. Rajendran, L. Sherry, and C. Williams, "Fungal biofilm resistance," International Journal of Microbiology, vol. 2012, Article ID 528521, 14 pages, 2012.

[99] B. Havlickova, V. A. Czaika, and M. Friedrich, "Epidemiological trends in skin mycoses worldwide," Mycoses, vol. 51, no. 4, pp. 2$15,2008$. 

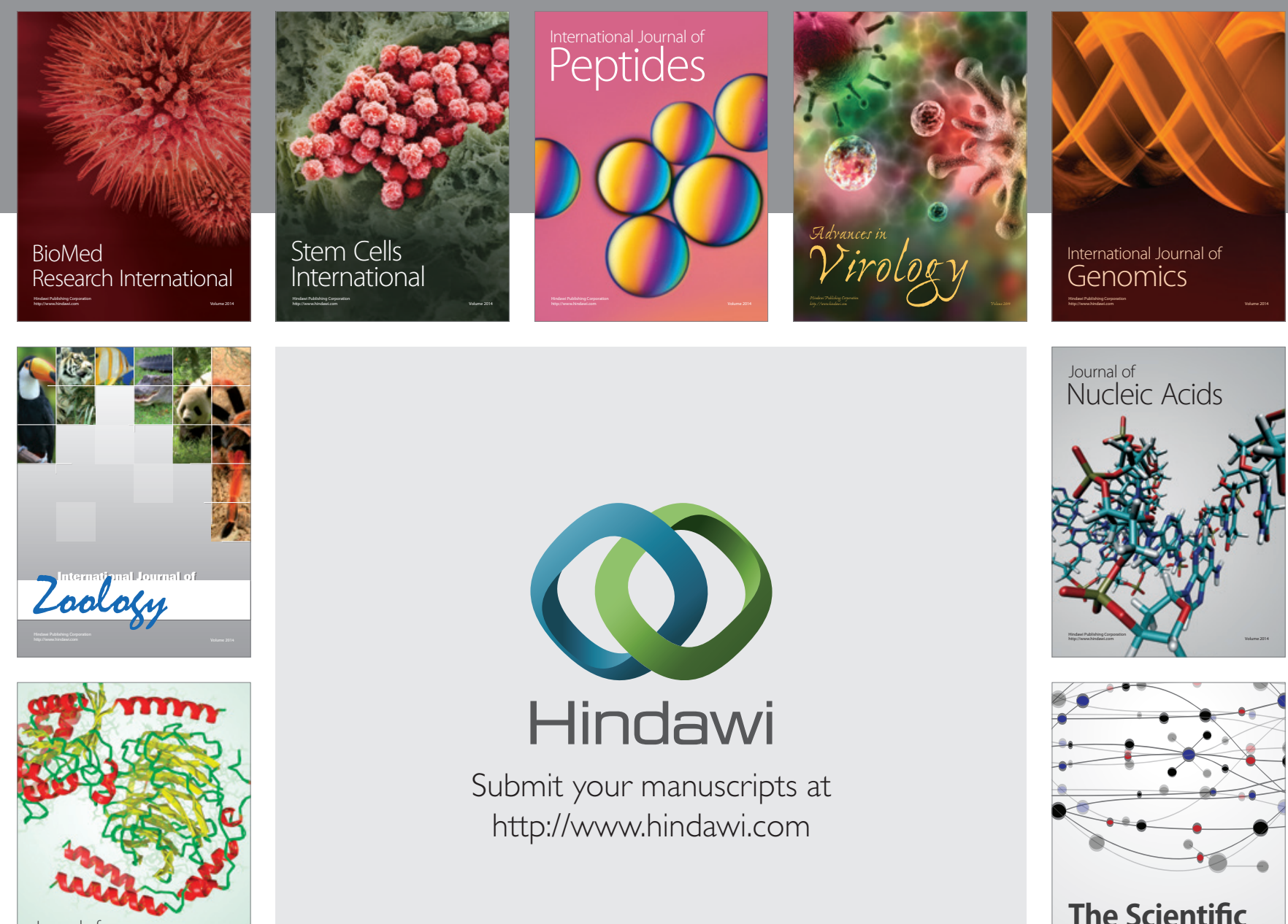

Submit your manuscripts at

http://www.hindawi.com

Journal of
Signal Transduction
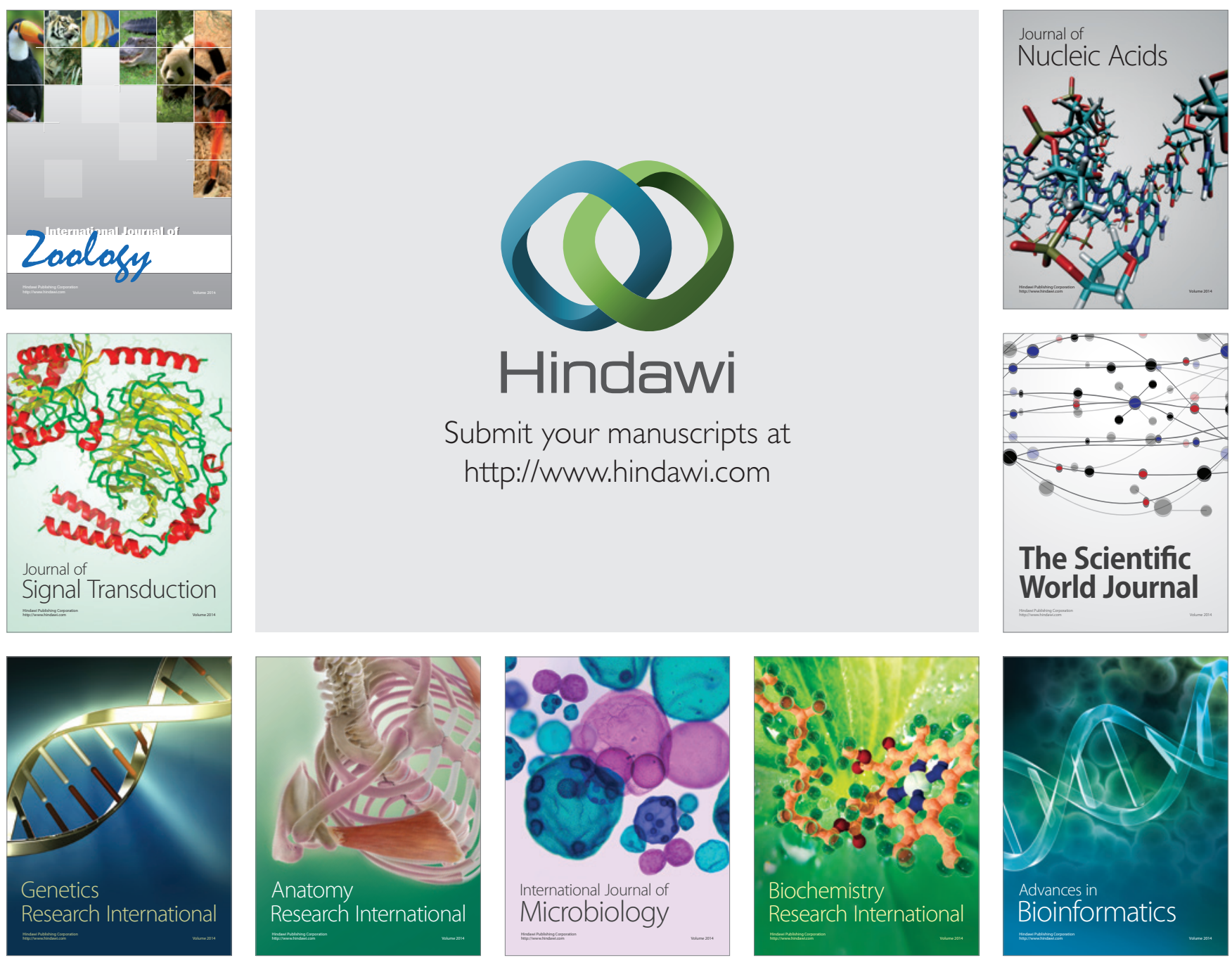

The Scientific World Journal
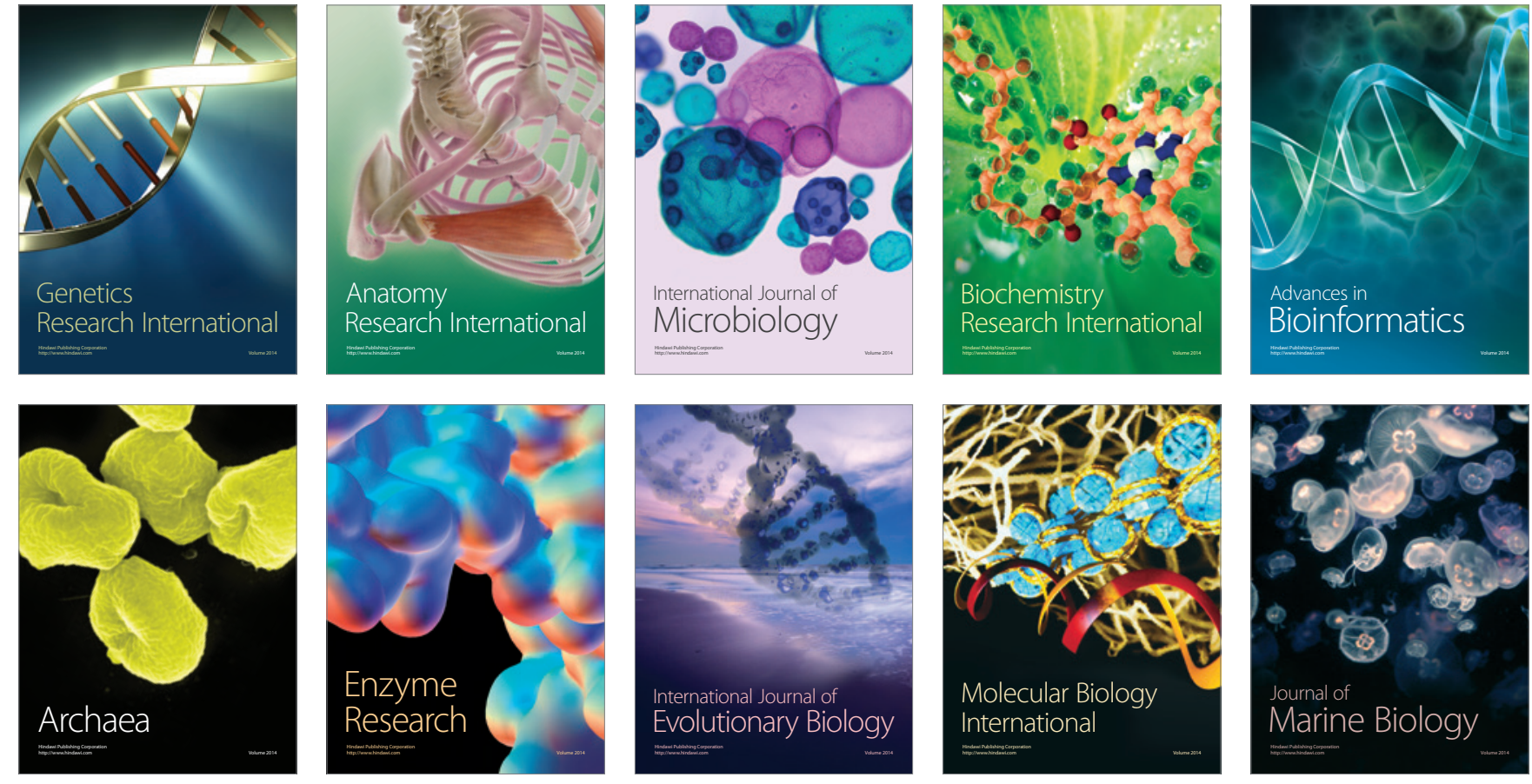